\title{
Therapeutische Umsehau
}

Therapeutische Notiz zur Krätzebehandlung.

Als billiges und gut wirkendes Mittel zur Krätzebehandlung hat bekannt-

lich Habermann an der Bonner Klinik eine Schwefelseiíen-Emvtlsion angegeben (Dtsch. med. Woch. 1916). Weitere Verstiche nachd.ieser Richtung haben ihn später dazii geführt, unter Fortlassung der Seife eine Schwefelmischung vonfolgender Zusammensetzung anzuwenden: Sulf. praec, Perka2lycerin od.er Mollphorus (eine Art Zuckersyrup), aa 60,0, Natr. carbonic. 3,0, Zinc, oxydat. 15,0, Calc. carbon. 30,0, Aqu. font, ad 300,0. Diese Mischung wird in 3 Tagen 6 mal eingepinselt und dann überpudert od.er nach Bedarf mit schwacher Salizyltumenol-Vaseline ( 2,2 bzw. 5 pCt.) oder Laneps nachbehandelt. Noch besser hat sich aber seit einer Reihe von Monaten eine ähnlich zusammengesetzte 5 proz. B-Naphtholmischung bewährt, die sehr billig und gut wirksam ist. Ihre Zusa,mmensetzung ist folgende: $\beta$-Naphthol $1 \delta, \mathrm{O}$, Mollphorvis 60,0, Natr. carbonic. 1,5, Zinc, oxydat. 30,0, Calc. carbon. 90,0, Aqua font, ad 300,0. Sie wird in 3 Tagen 5mal eingerieben, bei zu starkem Eintrocknen etwas Wasser nachgerieben; Bad am 4. Tag; später folgt leichtes Nachfetten mit Laneps und Pud,ern mit Talkum. Diese billige Behandlung kann bestens empfohlen werden. $\quad$ E. $H$. Personalien und Tagesnachriehten.

Der neu ernannte Direktor der Hautklinik in Breslau, Prof. Dr. Jarlas-sohn, erhielt den Titel Geheimer MedizineJrat.

Der bekannte Vorsteher des Moulageninstituts der Universität Wien, Dr. Karl Henning, ist im Alter von 58 Jahren gestorben; ebenso der Letter der Allgemeinen Poliklinik in Wien, Hofrat Prof. Anton v. Frisch, der sich d.urch die Entd.eckung des Rhinosklerombazillus ein besonderes Verdienst erworben hat.

In Bayem ist ein Lupus-Ausschuß gegründet worden, dem Geheimrat Dr. F. May als 1., Prof. L. v. Zumbusch als 2. Vorsitzender und Prof. K. Zieler als 1. Schriftführer angehören.

Am 23. V. fand in Berlin eine Sitzung des Lupus-Ausschusses des Deutschen Zentralkomitees zur Bekåmpfung der Tuberkulose statt, in welcher Dr. íS $1 / 8 \cdot \mathrm{cr} ø / \mathrm{J}-$ Barmen und Dr. WichmannHamburg über Erfolge und Aus-sichten der Chemo-Therapíe berichteten. 